\title{
Diel dive depth in penguins in relation to diel vertical migration of prey: whose dinner by candlelight?
}

\author{
Rory P. Wilson ${ }^{1,2}$, Klemens Puetz ${ }^{1}$, Charles A. Bost ${ }^{3}$, Boris M. Culik ${ }^{1}$, Rudolph Bannasch ${ }^{4}$, \\ Torsten Reins ${ }^{1}$, Dieter Adelung ${ }^{1}$ \\ ${ }^{1}$ Institut für Meereskunde, Düsternbrooker Weg 20, W-2300 Kiel 1, Germany \\ ${ }^{2}$ FitzPatrick Institute, University of Cape Town, Rondebosch 7700, South Africa \\ ${ }^{3}$ Centre d'Ecologie et Physiologie Energetiques, Centre National de la Recherche Scientifique, 23, rue Becquerel, F-67087 Strasbourg, France \\ ${ }^{4}$ FB10 Bionik, Technische Universität Berlin, Ackerstr. 71-76, W-1000 Berlin 65, Germany
}

\begin{abstract}
Diel vertical migration by zooplankton is thought to allow marine animals to exploit the more abundant food resources in the upper water strata at night while minimizing predation from optically orientating predators. Contrary to this, consistantly shallower dives at night made by marine reptiles, mammals, and birds have been attributed to enhanced feeding conditions as predators exploit prey that have become accessible near the surface. We found foraging success in penguins reduced at night and dive depth limited exclusively by ambient light levels. Consideration of foraging strategies adopted by air-breathing predators may explain typical vertical migration patterns of prey, as well as departures from them.
\end{abstract}

Diel vertical migrations of zooplankton and necton, in which organisms reside in deeper water strata during the day but rise to the surface by night, have been attributed to efficient utilisation of food resources near the surface (McLaren 1974) while minimizing predation from optically orientating predators (Gliwicz 1986). However, some species, despite being cited as conforming to this pattern, show partial diel vertical migration in that they frequent the upper water strata by night but distribute themselves over a wide variety of depths during the day (Kalinowski \& Witek 1980).

Mammals, birds and reptiles are major consumers in many marine ecosystems (e.g. Duffy et al. 1987, Huntley et al. 1991) and also show consistent periodicity in depth utilisation, diving deeper during the day than at night (Croxall et al. 1985, Eckert et al. 1988, Kooyman et al. 1992). This pattern is thought to occur because predators track prey throughout their diel vertical migrations (Croxall et al. 1985, 1988, Eckert et al. 1988, Kooyman et al. 1992). Nocturnal feeding in particular is considered to be facilitated as predators do not have to engage in energetically costly deep dives (e.g. Kooyman et al. 1992). This premise is, however, inconsistent with the hypothesis that many pelagic species minimize predation through diel vertical migrations (McLaren 1974, Gliwicz 1986).

We studied the foraging behavior of penguins to examine this inconsistency and to attempt to explain whether predator foraging tactics could account for partial diel vertical migration of prey

Materials and methods. Depth utilisation and foraging success were examined in 16 king (Aptenodytes patagonicus), 10 African (Spheniscus demersus), 18 Adelie (Pygoscelis adeliae), 14 gentoo (Pygoscelis papua) and 17 chinstrap (Pygoscelis antarctica) penguins at 3 different localities: king penguins at the Crozet Islands $\left(46^{\circ} 25^{\prime} \mathrm{S}, 51^{\circ} 40^{\prime} \mathrm{E}\right)$ between October and December 1991; African penguins at Dassen Island $\left(33^{\circ} 25^{\prime} \mathrm{S}, 18^{\circ} 05^{\prime} \mathrm{E}\right)$ during June 1991; and Adelie, gentoo and chinstrap penguins at Ardley Island (62 $\left.13^{\prime} \mathrm{S}, 58^{\circ} 55^{\prime} \mathrm{W}\right)$ during December 1991 and January 1992. All these penguin species feed on pelagic prey; king - lanternfish Myctophidae, African - cape anchovy Engraulis capensis, and Adelie, gentoo and chinstrap - Antarctic krill Euphausia superba (Croxall \& Lishman 1987). This was also ascertained for the study localities by stomach pumping (Wilson 1984) at least 8 individuals from each species. Lanternfish show full diel vertical migration (Zasel'sliy et al. 1985) whereas anchovy and krill, major primary consumers in upwelling (Crawford 1987) and Antarctic ecosystems (Everson et al. 1990) 
respectively, show partial diel vertical migrations (James 1987, Kalinowski \& Witek 1980).

Birds from each species were fitted with loggers (Driesen \& Kern GmbH, Wiesenweg 20, W-2000 Tangsted, Germany) which recorded information on dive depth, swim speed and, in some instances, light intensity at intervals of between 2 and $32 \mathrm{~s}$ while the birds were at sea. Additionally, birds were induced to swallow a second archival unit which logged stomach temperature (Wilson et al. 1992) at intervals of between 8 and $32 \mathrm{~s}$ (Elkutec Electronik GmbH, W-8057 Eching bei München, Germany). In marine endotherms, stomach temperature can indicate when prey is ingested since stomach temperatures drop markedly at this time (Wilson et al. 1992). Furthermore, the extent of the temperature drop and the time taken for the temperature to rise up to pre-ingestion levels can be used to approximate the mass of prey ingested (Wilson et al. 1992). Both units were recovered after birds had been absent at sea for 1 foraging trip.

Results and discussion. All 5 species of penguin showed changes in dive depth as a function of time of day which conformed with previously conducted studies (e.g. Figs. 1 \& 2) although maximum depth, both during the day and at night, varied between species. However, at night, when dives were most shallow and prey were expected to be near the surface, the birds fed little (e.g. Figs. 1 \& 2), and more importantly, had the lowest catch per unit effort. For example, Adelie penguins ingested ca 300 times more food per $\mathrm{km}$ swum from 10:00 to $14: 00$ as from 22:00 to $02: 00 \mathrm{~h}$. Thus, maximum dive depth at night is clearly not regulated by the vertical migration of prey as has been suggested (e.g. Kooyman et al. 1992). Rather, dive depth in penguins appeared dependent on light availability, which is a function of time of day and inversely correlated with water depth (Wilson et al. 1989) (Fig. 2). Reduced foraging success at night when birds dived only in the upper water strata implies that at this time prey preferred depths where light intensity was insufficient for penguins to effectively forage. Indeed, we speculate that avian predation pressure may act as a selective agent favouring vertical migration of prey.

However, contrary to the prey vertical migration hypothesis, it appears that predators are able to feed effectively by deep diving during the day. Airbreathing predators must return regularly to the surface to breathe so that exploitation of prey in deeper strata necessitates increased time and energy invested for transit. Thus, in the evolution of a vertical migratory habit by species that incur high mortality from airbreathing predators, there would be selection pressure to go increasingly deeper during the day. The depth to which prey should $\sin k$ will depend on relative costs

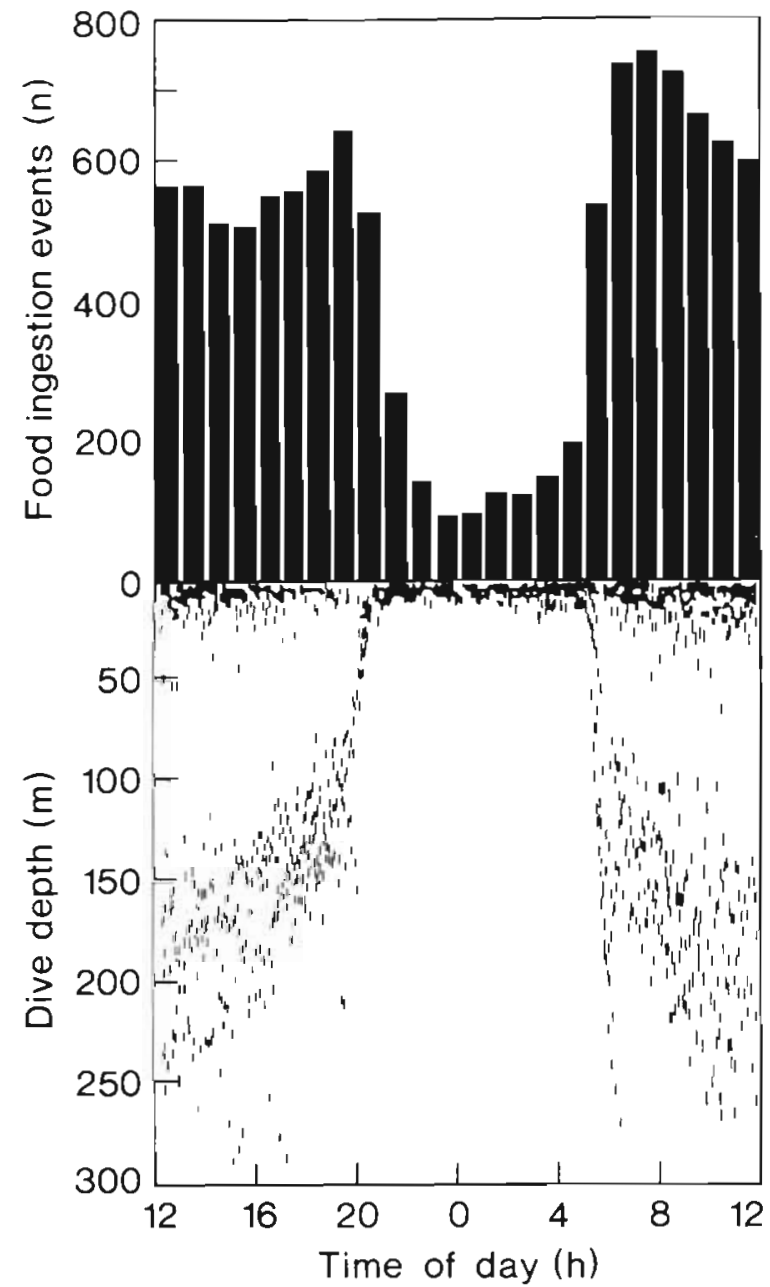

Fig. 1. Aptenodytes patagonicus. Number of prey ingestion events (top) and mean maximum dive depth (bottom) for king penguins foraging around the Crozet Islands as functions of local time (modified from Kooyman et al. 1992)

and benefits incurred from the energetic costs of migration, enhanced feeding in the different water strata and risk from predation. Predators feeding on such prey should direct dives to deeper strata during the day, as does the king penguin (Fig. 1) (Kooyman et al. 1992). The maximum depth reached by prey during the day may, however, be limited, either by unsuitable living conditions or by the sea bottom. The maximum depth at which krill are found is closely related to the oxygen content of the water since unadapted animals die at oxygen concentrations less than $85 \%$ (Kils 1979). At the South Shetland Islands this occurs at depths of less than $100 \mathrm{~m}$ (Kils 1979). Similarly, the African penguins that we studied were feeding in water that was less than $40 \mathrm{~m}$ deep so that in both instances the predators diving capabilities exceeded the maximum attainable depth of the prey. In these 


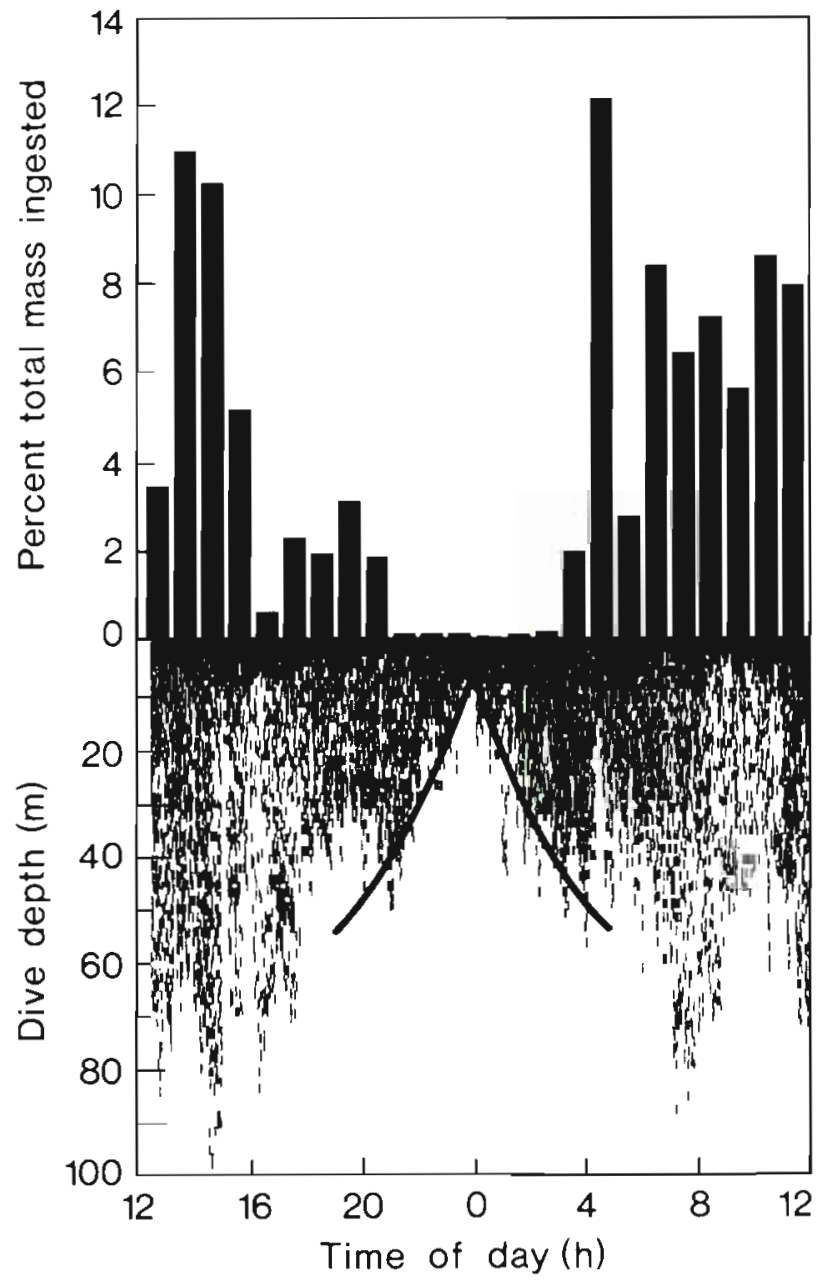

Fig. 2. Pygoscelis adeliae. Amount of food ingested (top) and dive depth (bottom) of Adelie penguins foraging around Ardley Island as a function of local time. The depth at which the 1 lux light level occurs (for 6 Jan 1992 - midway through our study) is indicated by the continuous line

cases another strategy is necessary to minimize chances of predation which must take into account the foraging strategy of the predators.

During normal prey searching behavior, all 5 penguin species showed the same patterns. Using the Adelie penguin to illustrate these patterns, swim speed was approximately constant $\left(x=2.2 \mathrm{~m} \mathrm{~s}^{-1}, \mathrm{SD}=0.45\right.$, $\mathrm{n}=785)$ and independent of maximum depth reached during the dive $\left(\mathrm{r}^{2}=0.02, \mathrm{p}>0.05\right)$. Birds typically executed ' $V$ '-shaped dives, where at the point of maximum depth they turned and returned immediately to the surface, or ' $U$ '-shaped dives where, at the deepest point of the dive, birds swam horizontally for a certain period. During any single dive, descent and ascent rates were constant, however, dive angles steepened with increasing maximum depth reached per dive [dive angle $\left(^{\circ}\right)=0.465$ depth $(\mathrm{m})+11.9 ; \mathrm{r}^{2}=0.33$, $\mathrm{p}<0.001, \mathrm{n}=785$ ] resulting in higher vertical velocities. In ' $U$ '-shaped dives vertical velocity changed at the deepest point of the dive to less than $0.1 \mathrm{~m} \mathrm{~s}^{-1}$ for a mean time of $41.5 \mathrm{~s}(\mathrm{SD}=15.1, \mathrm{n}=318)$. Consequently, penguins spent less time searching for prey in the upper water strata during deep as opposed to shallow dives (Fig. 3). Adelie penguins diving to $60 \mathrm{~m}$ spent only one-third as long searching the upper $10 \mathrm{~m}$ of the water column as birds diving to $20 \mathrm{~m}$. Thus, if predators dive deep, prey can reduce their chances of being detected by migrating nearer to the surface. In order to reduce predation over the $24 \mathrm{~h}$ light/dark cycle, prey should remain below the depth where ambient light prohibits effective predator foraging until light levels force prey to their maximum attainable depth, when subsequent dispersion throughout the water column would minimize chances of detection. If air-breathing vertebrates are indeed a major selective agent in determining the vertical migration of prey, we expect to observe general movement of prey closer to the water's surface around dusk and into deeper strata at dawn, followed by general dispersal later in the day. Antarctic krill conforms closely to this pattern in areas where krill maximum depth is limited by oceanographic features (Kalinowski \& Witek 1980). Conversely, we expect air-breathing predator foraging success to be reduced during the night, but to increase sharply at the time when increases in light levels permit effective foraging to take place at the maximum depth attainable by the prey (Fig. 2). This situation (Adelie, gentoo, chinstrap and African penguins) is distinct from the situation where prey may continue to move into deeper water (king penguins) and, in order

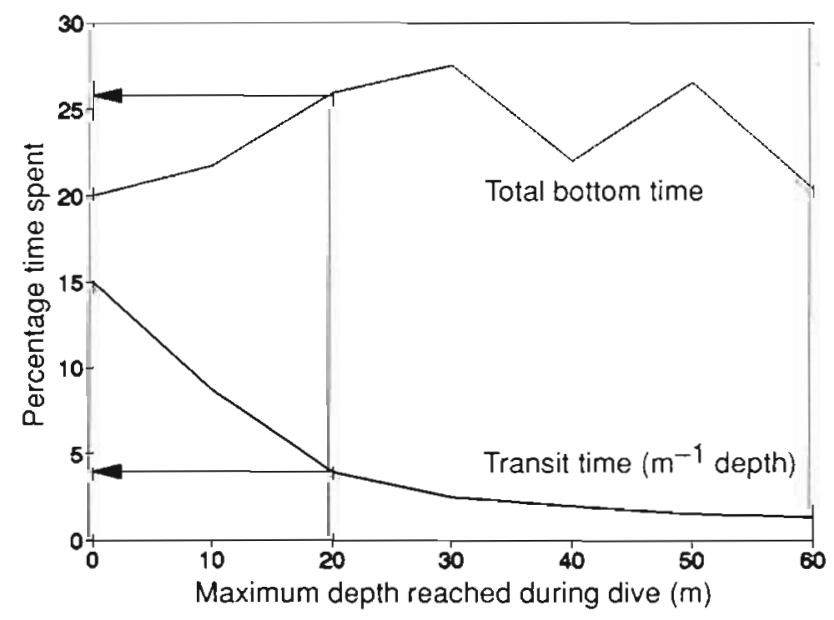

Fig. 3. Pygoscelis adeliae. Changes in transit time per metre depth and total bottom time in diving Adelie penguins $(\%$ of total dive time) as a function of maximum depth reached per dive (e.g. a bird diving to $20 \mathrm{~m}$ spends $3.9 \%$ of its time per metre, i.e. $74 \%$ during the first $19 \mathrm{~m}$ of transit and $26 \%$ of its time at the deepest point of the dive) 
to maximize the chances of prey detection, requires that predators direct dives to a variety of depths rather than to just one deep level (cf. Figs. 1 \& 2). Such hide and seek strategies are presumably highly dynamic and promise to be of great interest for future studies.

Acknowledgements. This study was supported by the Deutsche Forschungsgemeinschaft, the Benguela Ecology Programme of the South African National Committee for Oceanographic Research, the Centre National de la Recherche Scientifique, the European Economic Community and the Terres Australes et Antarctique Francaises and is dedicated to Prof. G. Hempel on his retirement as director of the Alfred Wegener Institute.

\section{LITERATURE CITED}

Crawford, R. J. M. (1987). Food and population variability in five regions supporting large stocks of anchovy, sardine and horse mackerel. S. Afr. J. mar. Sci. 5: 735-757

Croxall, J P., Davis, R. W., O'Conner, M. J. (1988). Diving patterns in relation to diet of Gentoo and Macaroni Penguins at South Gerogia. Condor 90: 157-167

Croxall, J. P., Everson, 1., Kooyman, G. L., Ricketts, C. (1985). Fur seal diving behaviour in relation to vertical distribution of krill. J. Anim. Ecol. 54: 1-8

Croxall, J. P., Lishman, G. S. (1987). The food and feeding ecology of penguins. In: Croxall, J. P. (ed.) Seabirds; feeding ecology and role in marine ecosystems. Cambridge Univ. Press, Cambridge, p. 101-134

Duffy, D. C., Siegfried, W. R., Jackson, S. (1987). Seabirds as consumers in the southern Benguela region. S. Afr. J. mar. Sci. 5: $771-790$

Eckert, S. A., Eckert, K. L., Ponganis, P., Kooyman, G. L.

This note was submitted to the editor
(1988). Diving and foraging behavior of leatherback sea turtles (Dermochelys coriacea). Can. J. Zool. 67: 2834-2840

Everson, J., Watkins, J. L., Bone, D. G., Foote, K. G. (1990). Implication of a new acoustic target strength for abundance estimates of Antarctic krill. Nature 345: 338-340

Gliwicz, M. Z. (1986). Predation and the evolution of vertical migration in zooplankton. Nature 320: 746-748

Huntley, M. E., Lopez, M. D. G., Karl, D. M. (1991). Top predators in the Southern Ocean: a major leak in the biological carbon pump. Science 253: 64-66

James, A. G. (1987). Feeding ecology, diet and field-based studies on feeding selectivity of the Cape Anchovy Engraulis capensis Gilchrist. S. Afr. J. mar. Sci. 5: 673-692

Kalinowski, J., Witek, Z. (1980). Diurnal vertical distribution of krill aggregations in the Western Antarctic. Pol. polar Res. 1: $127-146$

Kils, U. (1979) Performance of Antarctic krill Euphausea superba at different levels of oxygen saturation. Meeresforsch. 27:35-47

Kooyman, G. L., Cherel, Y., Le Maho, Y., Croxall, J. P., Thorson, P. H., Ridoux, V., Kooyman, C. A. (1992). Diving behavior and energetics during foraging cycles in king penguins. Ecol. Monogr. 62: 143-163

McLaren, I. A. (1974). Demographic strategy of vertical migration by a marine copepod. Am. Nat. 108: 91-102

Wilson, R. P. (1984). A new improved stomach pump for penguins and other seabirds. J. Field Orn. 55: 109-112

Wilson, R. P., Culik, B., Coria, N. R., Adelung, D., Spairani, H. J. (1989). Activity rhythms in Adelie Penguins at Hope Bay, Antarctica; determination and control. Polar Biol. 10: 161-165

Wilson, R. P., Ploetz, J., Cooper, J. (1992). Can we determine when marine endotherms feed? A case study with seabirds. J. exp. Biol. 167: 267-275

Zasel'sliy, V. S., Kudrin, B. D., Poletayev, V. A., Chechenin, S. (1985). Some features of the biology of Electrona carlsbergi (Taning) (Myctophidae) in the Atlantic sector of the Antarctic. J. Ichthyol. 25: 163-166

Manuscript first received: October 5, 1992

Revised version accepted: January 19, 1993 